\title{
Creating a new future: Redeveloping the tribal-museum relationship in the time of NAGPRA
}

\author{
Wendy Giddens Teeter ${ }^{1 *}$ (D), Desiree Martinez (Tongva) ${ }^{2}$ and Dorothy Lippert (Choctaw) ${ }^{3}$ \\ ${ }^{1}$ Fowler Museum, University of California Los Angeles, United States \\ ${ }^{2}$ Cogstone Resource Management, Orange, CA, United States \\ ${ }^{3}$ Smithsonian National Museum of Natural History, Washington, DC, United States \\ *Corresponding author. Email: wteeter@arts.ucla.edu
}

\begin{abstract}
The hope has long been that the Native American Graves Protection and Repatriation Act (NAGPRA) would finally bring ancestors and their cultural items home to their communities to be reconnected and rest. However, 30 years later, museums and academics still fear losing control of research and access in their intellectual pursuits. Far from true, museums have benefited in working with tribes in telling stories around their cultural history, present and future. This article shares experiences over the authors' careers and counters the alarmist calls to arms against compliance with NAGPRA.
\end{abstract}

Keywords: NAGPRA; repatriation; museums; collaboration; Native American tribes

Since the passage of the Native American Graves Protection and Repatriation Act (NAGPRA) in 1990, many Native American, Native Hawaiian, and Alaska Native community members thought that their ancestors and their cultural items would finally be removed from museum shelves and returned to their communities for reburial under the force of law. ${ }^{1}$ This goal was hindered as some museum officials focused on how to minimize or evade NAGPRA compliance. ${ }^{2}$ This reluctance to comply included the fear of losing control over their "best" objects, the curtailment of new research, and offending their donors. ${ }^{3}$ While ancestors and their belongings have been returned to their descendants over the last 30 years, there have been unanticipated benefits to museums. Continuous discussions with tribes and Indigenous communities, initiated through NAGPRA consultation, have resulted in more innovative and collaborative exhibitions and programming, a holistic approach to collection curation that includes cultural sensitivity and respect, and revamped and expanded interpretative materials that discuss Indigenous communities' present and future, not just their past. A number of recent publications ignore these unanticipated benefits and continue to foster alarmist calls to arms against compliance with NAGPRA.

Based on decades of professional experience as museum staff, archaeology professionals, repatriation compliance officials, and tribal members, the authors will highlight

\footnotetext{
${ }^{1}$ Native American Graves Protection and Repatriation Act (NAGPRA), 16 November 1990, 104 Stat. 3048, https:// www.govtrack.us/congress/bills/101/hr5237.

${ }^{2}$ Colwell 2017.

${ }^{3}$ Nash and Colwell-Chanthaphonh 2010.
}

(C) The Author(s), 2021. Published by Cambridge University Press on behalf of the International Cultural Property Society. This is an Open Access article, distributed under the terms of the Creative Commons Attribution licence (http://creativecommons.org/ licenses/by/4.0/), which permits unrestricted re-use, distribution, and reproduction in any medium, provided the original work is properly cited. 
some of the unique and collaborative work that has occurred between museums and tribes since the passage of NAGPRA. As the repatriation officer for the University of California Los Angeles (UCLA) since 1997, Wendy Teeter has led the return of thousands of ancestral remains and hundreds of thousands of objects to tribes and has provided her repatriation expertise to tribes, museums, and federal and state agencies. Desiree Martinez is a Gabrielino (Tongva) community member, register professional archaeologist, former museum professional, and has participated in the NAGPRA claim process both as a claimant and as a liaison for other Native American communities. Dorothy Lippert is a citizen of the Choctaw Nation of Oklahoma and has worked in the repatriation office of the National Museum of Natural History at the Smithsonian Institution for nearly 20 years. As practicing Indigenous archaeologists, the authors have seen that tribes and Indigenous communities have been able to renew their relationship with, and their responsibilities to, their ancestors and belongings as well as have more direct control over their cultural heritage. Additionally, museums and academics are engaging in longterm reciprocal community-based participatory research. We review some of these developments below.

\section{Acknowledgment of subpar curation standards}

NAGPRA charged museums and other institutions that received federal funds to create inventories and summaries of human remains and NAGPRA-eligible items (funerary objects, objects of cultural patrimony, and sacred items) under their control. As these inventories and summaries were completed, the subpar conditions of archaeological collections were exposed, most remaining in their original disintegrating paper bags. Before 1990, there was no standard practice for care of archaeology collections. ${ }^{4}$ This situation changed with the passage of the Curation of Federally Owned and Administered Archaeological Collections Regulations in 1990, which established standards and guidelines for the management and preservation of collections from federal lands in both federally owned and public or private repositories that held federal collections. ${ }^{5}$ These regulations were the first of their kind, but they set no deadlines for compliance or enforcement provisions. ${ }^{6}$

Although the Archaeological Collections Regulations provide standards of curation, there are still many museums and repositories that do not meet this minimum threshold. Collections care often varies with the financial health and staffing levels of the institution. Archaeology collections curated after 1990 through cultural resource management projects began to slowly arrive in polyethylene bags with a field catalog and, at minimum, in acidfree boxes. The condition of academically excavated material continued to lag behind CRM objects unless the repositories demanded these minimal curatorial standards prior to accessioning into their collections. Otherwise, it was often only well-staffed and funded museums that could re-catalog and safely re-house older collections and appropriately register the associated documentation. ${ }^{7}$ Until 1990, collections that were accepted earlier in the museum's life often remained in the same state and within the same packaging in which they arrived. By requiring museums to create inventories and summaries, NAGPRA forced museums to review all the North American collections in their care, prioritizing funding and staff and beginning to formulate a comprehensive overview of what was within their possession and control.

\footnotetext{
${ }^{4}$ Sullivan and Childs 2003; Childs 2004.

${ }^{5}$ Curation of Federally Owned and Administered Archaeological Collections Regulations, 12 September 1990, 36 CFR Part 79, https://www.law.cornell.edu/cfr/text/36/part-79.

${ }^{6}$ Childs 2004; Teeter 2011.

${ }^{7}$ Goeman-Shulsky and Teeter 2019.
} 
While archaeological collections were curated in museums for their potential to answer future research questions, very rarely were they used. Instead, universities compelled graduate students to conduct new excavations to better fit their archaeological methods and techniques and obtain new data for their research questions. Using existing museum collections to answer research questions, let alone asking permission and collaborating with the affiliated descendent community prior to engaging with the material was almost never considered an option.

\section{Discovery of missing provenance and provenience of collections}

In order to ensure that the ancestors and their belongings are returned to the correct Tribal communities, an investigation of collection provenience and provenance - where collections came from; the location of burials and burial items within the site; and when, why, and who had control over collection disposition and care - must occur. ${ }^{8}$ Additionally, creating NAGPRA inventories requires knowing what research and analysis has been previously completed, their results, and what has happened to the samples as well as if they were sent to another institution for specialized research (for example, carbon-14).

When co-author Wendy Teeter was hired to assist with the compliance of NAGPRA at UCLA, the archaeology collections were stored on old wooden trays, objects were directly inked with a catalog code, and hand-written field catalogs were the only reference to where objects came from and where they were stored within the museum. Items at times dropped behind the trays and were only discovered during a move in 1999. At that time, human remains were also found stored inside an unused air duct. Prior to 1990, collection items that were "loaned" for research, destructive analysis, or class projects were recorded on loan forms and kept separate from collection files with little follow-up to ensure their return. No investment beyond a halftime graduate student assistant was provided for these collections. NAGPRA and the Archaeological Collections Regulations mandated staff support to inventory, rehouse, chase down loans, locate old reports and missing items, and review excavation permits and other basic acquisition data in order to provide required information to begin consulting with tribes. The care of collections at UCLA at that time was typical of both small and large universities. Unless there was initiative and funding to comply, either from the university or departmental leadership, compliance was not going to happen.

Often decried as an unfunded mandate, NAGPRA provides grants, administered through the National Park Service, for compliance efforts and consultation between tribes and museums as well as tribal support for reburial costs. When museums and universities have received these funds, they have been able to complete the work of accessioning and cataloging archaeological materials in collaboration with tribes. It was a fallacy that all the best archaeological materials would be repatriated based on religious grounds, but there still are many cases where funerary objects and even human remains have gone unidentified within a broader collection because of this fear. In denouncing site looting, archaeologists lament the loss of information that would otherwise be attached to artifacts. Yet collections that languished without proper cataloging and curation were little better in their scientific value, as the provenience decayed in original non-archival packaging and, unfortunately, was too often subjected to rodents and insect infestations. In contrast, the work of preparing the summaries and inventories produced a great amount of information for museums and researchers about these undervalued cultural items.

\footnotetext{
${ }^{8}$ Martinez 2010; Martinez, Giddens Teeter, and Kennedy-Richardson 2014.
} 


\section{Renewed interest in research potential of collections}

The intent of NAGPRA was not to conduct new research on Native American human remains and cultural objects. However, while examining collections to determine what was subject to the law, reviewing associated documents, and documenting information gathered during tribal consultations, museum staff and researchers, along with tribal representatives, obtained a better understanding of this cultural heritage, how items were made and used, and the role they played within the tribal community from which they came. Excitement over these new connections and perspectives has led to new collaborative research. The number of projects using or discussing Native American remains and belongings surged as museums complied with NAGPRA and identified what was held in these repositories, often for the first time since they arrived. In some cases, items that were considered highly valued research materials were misplaced over the years only to be recovered as spaces were cleared out and loans interrogated and recalled for inventory purposes.

The cultural items and human remains in museum collections are there because they were once Native American people and their belongings. Indigenous people retain this perspective. For tribes, NAGPRA consultation can provide answers to long known stories about the removal of ancestors and their belongings from villages and other special places over the years. They knew they were removed, but where did they go? Access and the ability to request their return in NAGPRA gives tribes a voice that has often been ignored in these conversations. ${ }^{9}$ Museum staff working in repatriation may come to respect this knowledge and history, allowing it to enrich their work with collections. In essence, repatriation work can make people better collection care providers.

\section{Initiating, building, and solidifying relationships}

Through NAGPRA consultation, a major shift has occurred allowing tribes and Indigenous communities to reconnect with their ancestors and cultural items and control access, arrange for appropriate cultural care, and inform interpretation. Beyond identifying who was culturally connected with places and collections, it has allowed Indigenous people to share their living memories and responsibilities to these locations, ancestors, and belongings as well as determining if they should be used in exhibitions, research, programs, and education. To reduce misunderstandings, tribal permissions have become more commonplace before research or display occurs on NAGPRA eligible or potentially eligible collections in museums and repositories. In some cases, museums require tribal permission prior to any use of culturally affiliated Native American collections. At the Fowler Museum, for example, when inventories were updated and collection information consolidated, research requests increased significantly. Acknowledging the special relationship that culturally affiliated tribes have with collections under the Fowler Museum's control, permission letters from tribes were requested before research and/or destructive analysis could be conducted. In return, tribes asked questions about research goals and rationale and requested regular updates on progress and copies of results.

While there was initial fear that tribes would prevent research or prevent the publication of results, more often they asked that objectives be modified and interpretations of results be discussed with tribes before final conclusions were made. Sometimes, they requested a presentation be made for a tribal audience. Importantly, traditional knowledge and expertise is recognized for its connections to the past, present, and future generations and to the research being created. Science is supposed to allow for the inclusion of all knowledge systems. It has often been the researcher's underlying Western paradigm that has limited

\footnotetext{
${ }^{9}$ Martinez 2006; Teeter and Martinez 2009.
} 


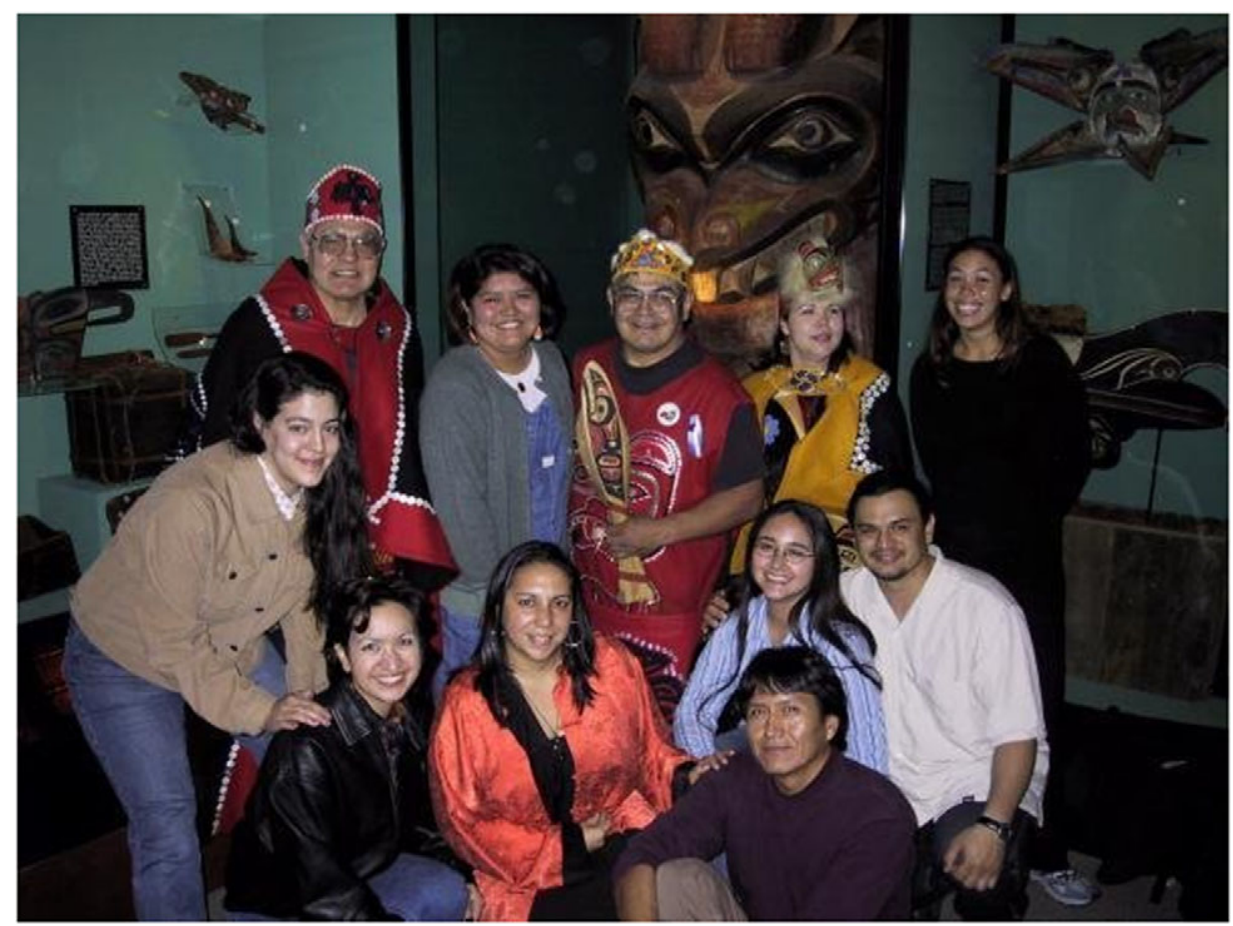

Figure I. Members of the Harvard University Native American Program with members of the Saanya Kwaan Teikweidi clan, 200I (photograph courtesy of Desiree Martinez).

understandings of the past and problem-solving solutions. This has been a great learning opportunity for graduate students, who often continue to have long relationships with these tribes after their initial research project.

Through consultations with museums, tribes provided and developed protocols for traditional care of their cultural heritage that allowed for deeper partnerships beyond NAGPRA. Proscriptions such as requesting the use of natural storage materials instead of plastics, asking that particular items face certain directions, providing restricted access, and requesting the end of practices that would prevent the natural decay of living objects in museums are easy to accommodate with available staff and space. Most museums have stopped living in fear of "outrageous" tribal demands and realized that over the decades both have grown to understand the needs, limitations, and valuable expertise to develop achievable goals. For instance, the Museum of Anthropology at the University of British Columbia has made ceremonial items available for loan to appropriate First Nation individuals as needed and purchased important new cultural items on request from the clan, village, or creator.

In another example of creative collaboration, a memorial clan crest (previously known as a totem pole) belonging to the Teikweidi Saanya Kwaan clan from the Tlingit Gaash Village near Cape Fox, Alaska was owned and displayed at the Harvard Peabody Museum for 100 years. ${ }^{10}$ As a clan-owned item, the crest was considered an item of cultural patrimony under NAGPRA, an item that could not be given away without the permission of the clan. The Cape Fox Corporation made a NAGPRA claim for the crest on behalf of the Teikweidi Saanya

${ }^{10}$ See "NAGPRA in the Museum Galleries," https://www.peabody.harvard.edu/node/313. 
Kwaan clan, and it was returned. As a gesture of good will and to revitalize the relationship between the Peabody and the Teikweidi Saanya Kwaan clan, the Cape Fox Corporation gifted a cedar tree pole to the Peabody. The Peabody then commissioned Master Tlingit Carver Nathan Jackson to carve the pole. The new pole, which is entitled "Kaats' and Brown Bear Totem Pole (Kaats' Xóots Kooteeya)," tells the same story as the pole repatriated. Jackson started the carving in his studio and completed it in the Peabody Museum galley. This gave museum visitors and Harvard Native American students a unique opportunity to watch a master at work and to learn about the meaning of the crest and the importance of returning the crest to the Teikweidi Saanya Kwaan clan (Figure 1). While the law only requires the return of a cultural item unlawfully removed, this collaborative and generous outcome provided audiences, staff, and students with rich experiences and opportunities to learn about Native American histories and living people. The relationships developed during these moments are often sustained through ongoing engagements and collaborations that go way beyond NAGPRA.

\section{Meeting tribal needs, answering tribal questions}

While conversations with tribes and museum staff deepened, reciprocal relationships have developed. Tribes often felt used by researchers, mined for their cultural data and knowledge, with researchers building their careers without acknowledging the origin of their data or providing a benefit to the Indigenous community affiliated with the work. With the help of NAGPRA, tribes are demanding a paradigm that adheres to community-based research protocols and Indigenous methodologies. ${ }^{11}$ These efforts mean that research is designed in collaboration with the Indigenous communities with aspects of the effort that benefit the community. ${ }^{12}$ Community-based research with Indigenous communities includes their participation at all stages, from the development of the research questions and goals to disseminating the results to the community and the public. In order to obtain meaningful tribal collaboration, research grants should include financial support for Indigenous participation. This support acknowledges that tribal knowledge and expertise is valued just as much as knowledge obtained by Western science.

In the Fowler Museum, Teeter acknowledges that her career has benefited especially from working with the Tongva community and being a part of American Indian Studies at UCLA. One important aspect of this work was the recognition that archaeology almost never specifies that it interacts with living community members who have valuable expertise to provide. As such, archaeology research projects should first consult with descendent community members and go through an Internal Review Board process. Recognizing the connection between living people and the past humanizes this work and recognizes the impact it has on present and future generations. For this reason, Teeter ensures that her publications and projects are collaborations, which is a huge shift from traditional academic practice and one that goes against the single author requirement for humanities academic promotion. In 2007, Teeter and Martinez formed the Pimu Catalina Island Archaeology Project (PCIAP) with members of the Ti'at Society (a Tongva maritime organization) to reexamine previous excavations and landscapes on Santa Catalina Island, located off the coast of southern California and part of Tongva (Gabrielino) territory, and to incorporate Tongva and the surrounding tribal traditional knowledge and stories. ${ }^{13}$ The PCIAP's goals were formed by, for, and with the Tongva community as well as in collaboration with the Santa Catalina Island Conservancy, the land manager of 88 percent of Santa Catalina Island.

\footnotetext{
${ }^{11}$ Chari and Lavallee 2013.

${ }^{12}$ Nicholas 2010; Atalay 2012; Wobst, Bruchac, and Hart 2016.

${ }^{13}$ Marsa 2014.
} 
Far from a removed and forgotten past, stories, songs, and ceremonies emerged once they were asked for, and they deepened the understanding of how the Southern Channel Islands were viewed and valued by many communities.

As detailed in his talk entitled "Community Collaborations: Alaska Native Artistic Revitalization" for the School of Advanced Research, Sven Hakkanson describes how, during a 2003 NAGPRA consultation visit to the Harvard Peabody Museum with Alutiiq tribal leaders, they identified a single person kayak (qayanquaq), which is one of only two known in the world. ${ }^{14}$ This identification resulted in a collaboration between the Peabody staff and Alutiiq community members to restore the kayak with the hope that it would be permanently loaned to the Alutiiq community on Kodiak Island. During the restoration, Alutiiq kayak builder Alfred Naumoff saw construction techniques that he had never seen before and was able to utilize those techniques in his future builds and taught those techniques to Alutiiq youth. Such reconnections between cultural members and their heritage demonstrate the living communication that can occur when people are able to access these cultural objects that have been kept from them for too long.

\section{Exploring the impacts of repatriation to tribal communities and beyond}

Carrying our Ancestors Home (CoAH) is a project UCLA's Teeter, Mishuana Goeman, and Sedonna Goeman-Shulsky developed, and continues to develop, in collaboration with tribes and Indigenous communities because of NAGPRA. ${ }^{15} \mathrm{COAH}$ documents how repatriation affects Indigenous communities and their members. Scholarship regarding repatriation is often written by academics and museum staff for academic and museum audiences, focusing on how museums have been impacted (loss of finances, loss of control, and loss of research potential, to name a few). Very rarely do these published reports engage tribal community members, or, if they do, tribal voices are used to support predetermined perspectives and theories. Chumash, Tongva, Tataviam, and Serrano tribal members acknowledged this issue after partnering with UCLA to reinter their ancestors and belongings in 2016. They saw little discussion in written reports or presentations about how witnessing the historical illtreatment of the ancestors and the preparation of the ancestors and their belongings for reburial is a grueling process, taking an emotional, physical, mental, and spiritual toll on all involved. To note, Eric Hemenway is one of the few Native authors that has shared his incredible experiences as a tribal repatriation officer. ${ }^{16}$

Goeman, Goeman-Shulsky, and Teeter reached out to a host of tribal partners and organizations, such as the Association on American Indian Affairs, to discuss the best way to bring these impacts, and others, to the forefront in order to create a resource available to tribal members conducting this work as well as to educate non-Native museum staff, academics, and students on these hidden issues. A public website was identified as the best way to get information to an international audience. CoAH includes a series of short videos defining NAGPRA and describing what repatriation work means to tribal practitioners as well as other important topics. The work is ambitious as it discusses repatriation not only in the United States but also internationally with the Rapa Nui Repatriation Program and members of Te Papa in New Zealand. CoAH also includes educational resources and citations, classroom materials, and, most importantly, an opportunity for sharing the foundational perversity of having to reinter your ancestors after they were laid to rest so long ago. The fundamental premise of $\mathrm{COAH}$ is to provide a space for healing, to acknowledge the trauma

\footnotetext{
${ }^{14}$ See "Community Collaborations Alaska Native Artistic Revitalization," https://www.youtube.com/watch?v= c1g0EQqpklw.

15 “Carrying our Ancestors Home," https://coah-repat.com.

${ }^{16}$ Hemenway 2013.
} 
created by having to deal with the desecration of Indigenous graves and sacred spaces, and to share how their tribal community has coped.

\section{Conclusion}

The passage of NAGPRA acknowledges that Indigenous people have been subject to genocide and not only survived but also remain here to tell their stories, past, present, and future. Complying with NAGPRA is a beginning for museums, repositories, and academia to accept their complicity in, and benefits from, these colonial acts of erasure and harm. Many nonNative scholars still find this too difficult to acknowledge, and some continue to undermine the recognition of repatriation as a basic human rights endeavor. Shannon Keller O'Loughlin, director of the Association on American Indian Affairs, often publicly says: "NAGPRA is a floor, not a ceiling." From this perspective, a great deal of creative and incredible collaborative work has been achieved. Through the examples above and through articles in this special edition, the transformative benefit of this law can be recognized. The healing and positive relationships that continue to be forged between museums and tribes are innumerous. Ancestral remains and their belongings have been laid to rest, and new innovations based on traditional designs and recaptured techniques have produced incredible cultural objects. Language and stories are shared once again, and the land remembered in context.

Likewise, archaeological and ethnographic objects acquired and often pushed to the side for newer collections are receiving critical attention and funding. The effects of the curation crisis on collections management went unchecked for decades. Tribal involvement in management and requirements to comply with federal and sometimes state cultural laws has meant that museum/repository collection managers and curators have the support to request funds for better care. New research and interpretation with tribes and Indigenous communities create more meaningful goals and questions that benefit not just the researcher but also the tribal community. Overall, the general public receives richer narratives that recontextualize cultural objects, showing their relationships with living people.

\section{Bibliography}

Atalay, Sonya. 2012. Community-Based Archaeology. Berkeley: University of California Press.

Chari, Sangita, and Jaime Lavallee, eds. 2013. Accomplishing NAGPRA: Perspectives on the Intent, Impact, and Future of the Native American Graves Protection and Repatriation Act. Corvallis: Oregon State University Press.

Childs, S. Terry. 2004. Our Collective Responsibility: The Ethics and Practice of Archaeological Collections Stewardship. Washington, DC: Society for American Archaeology.

Colwell, Chip. 2017. Plundered Skulls and Stolen Spirits: Inside the Fight to Reclaim Native America's Culture. Chicago: University of Chicago Press.

Goeman-Shulsky, Sedonna, and Wendy Teeter. 2019. Curation in Crisis: Knowing the Unknown through Potential Solutions. https://www.fowler.ucla.edu/archaeology/sca-curation-2019-survey/.

Hemenway, Eric. 2013. "Finding our Way Home." In Accomplishing NAGPRA: Perspectives on the Intent, Impact, and Future of the Native American Graves Protection and Repatriation Act, edited by Sangita Chari and Jaime Lavallee, 83-98. Corvallis: Oregon State University Press.

Marsa, Linda. 2014. "Reinterpreting an Ancient Island.” American Archaeology (Winter): 19-23.

Martinez, Desiree Renee. 2006. "Overcoming Hindrances to Our Enduring Responsibility to the Ancestors: Protecting Traditional Cultural Places (Special Issue: Decolonizing Archaeology).” American Indian Quarterly 30, no. 3: 486-503.

Martinez, Desiree Renee. 2010. “(Re)searching for Ancestors through Archaeology.” In Being and Becoming Indigenous Archaeologists, edited by George Nicholas, 210-21. Lanham, MD: AltaMira Press.

Martinez, Desiree Renee, Wendy Giddens Teeter, and Karimah Kennedy-Richardson. 2014. "Returning the tataayiyam honuuka' (Ancestors) to the Correct Home: The Importance of Background Investigations for NAGPRA Claims." Curator: The Museum Journal 57: 199-211. 
Nash, Stephen E., and Chip Colwell-Chanthaphonh. 2010. “Editorial: NAGPRA after Two Decades." Museum Anthropology 33, no. 2: 99-104.

Nicholas, George P, ed. 2010. Being and Becoming Indigenous Archaeologists. Walnut Creek, CA: Left Coast Press.

Sullivan, Lynne P., and S. Terry Childs. 2003. Curating Archeological Collections: From the Field to the Repository. Lanham, MD: AltaMira Press.

Teeter, Wendy G. 2011. "This Belongs in a Museum? Portable Cultural Property." In A Companion to Cultural Resource Management, edited by Thomas F. King, 141-55. Hoboken, NJ: Wiley-Blackwell.

Teeter, Wendy G., and Desiree R. Martinez. 2009. "Native American Perspectives of California Archaeology." In Archaeology in America Encyclopedia, edited by L. S. Cordell, K. Lightfoot, F. McManamon, and G. Milner, 20-26. Santa Barbara, CA: Greenwood Publishing.

Wobst, H. Martin, Margaret Bruchac, and Siobhan Hart, eds. 2016. Indigenous Archaeologies: A Reader on Decolonization. London: Taylor \& Francis.

Cite this article: Teeter, Wendy, Desiree Martinez, and Dorothy Lippert. 2021. "Creating a new future: Redeveloping the tribal-museum relationship in the time of NAGPRA." International Journal of Cultural Property 28, no. 2: 201-209. https://doi.org/10.1017/S0940739121000242 